\title{
Prevalence of foodborne bacteria isolated from fresh raw ulam
}

\author{
${ }^{1}$ Bahri, A.A., ${ }^{1, * W a n}$ Abdullah, W.Z., ${ }^{1}$ Lani, M.N. and ${ }^{2}$ Salleh, W. \\ ${ }^{1}$ Faculty of Fisheries and Food Sciences, Universiti Malaysia Terengganu, 21030 Kuala Nerus, \\ Terengganu, Malaysia. \\ ${ }^{2}$ Terengganu Food Safety and Quality Laboratory, Ministry of Health Malaysia, 21200 Kuala \\ Terengganu, Terengganu, Malaysia
}

\begin{abstract}
Article history:
Received: 24 December 2020

Received in revised form: 24

February 2021

Accepted: 29 May 2021

Available Online: 16 January 2022
\end{abstract}

Keywords:

Vegetable,

Ulam,

Prevalence,

Foodborne bacteria

DOI:

https://doi.org/10.26656/fr.2017.6(1).766

\begin{abstract}
Although vegetables are considered to be an essential part of a healthy diet, studies have shown that they can also represent a hazard for human health as they are usually eaten raw and receive minimal treatment. In recent years, vegetables are among the food groups associated with higher rates of recurrence and are the leading cause of enteric diseases. There is a colossal amount of data available on fresh produce worldwide; however, limited data are available regarding the microbiological quality of ulam in Malaysia. In fact, cross -contamination that occurs during minimal processing of ulam has not yet been studied. Therefore, the aim of this study was to evaluate the microbiological quality and the occurrence of Escherichia coli and Salmonella in ulam. A total of 32 samples of ulam were randomly collected from wet markets and supermarkets in Kuala Terengganu, Malaysia. The samples were analysed for enumeration of aerobic mesophilic bacteria, coliforms, yeast and moulds, Bacillus cereus, Listeria monocytogenes and detection of Escherichia coli and Salmonella. In this study, the microbiological quality of ulam were in the range of $6.36-8.83 ; 4.14-7.48 ; 0-8.16 ; 3.94-6.45 \log _{10} \mathrm{CFU} / \mathrm{g}$ for aerobic mesophilic bacteria, coliforms, Salmonella and yeast and moulds, respectively. Escherichia coli and Salmonella were detected in $3.13 \%$ and $9.4 \%$ of ulam samples, respectively. The findings from the study are intended to provide insight into the potential health risks associated with the consumption of ulam. The strong interdisciplinary approach by various agencies and development of safe agricultural systems will ensure the delivery of safe vegetables to the end-users.
\end{abstract}

\section{Introduction}

Herbs or ulam are important food intakes among the Malays because of their nutritional value. They provide proteins, fibre, sugar, minerals and many vitamins, which are essential to promote health for human life (Gruda, 2005; Bachok et al., 2014). Even though ulam can promote good health, ulam that is usually eaten raw and without enough heating process may be contaminated with a wide range of microorganisms, including foodborne bacteria. The contamination of vegetables may occur at any stage, including during pre and post-harvest handling (Chaturvedi et al., 2013). As a result, the foodborne disease outbreaks linked to fresh produce have also increased. The Center for Science in the Public Interest (CSPI) published a report stating that 363 outbreaks and 13,568 cases of illness were related to green leafy vegetables. These ranked them number one in the United States of America (USA) Food and Drug Administration (FDA) Top Ten (Center for Science in the Center for Science in the Public Interest., 2009). In Malaysia, the information of foodborne outbreaks related to the consumption of fresh produce was unknown. When an outbreak occurred, little attempt was made to discover the magnitude of the problem and source of the outbreak, likely due to the isolation and identification process of microorganisms that is time-consuming (Kuan et al., 2017; New et al., 2017).

Over the past decade, several foodborne bacteria commonly detected in fresh vegetables include E. coli, Salmonella spp., Shigella, Bacillus and Listeria monocytogenes (Mritunjay and Kumar, 2015). Escherichia coli and Salmonella are among the most frequent foodborne bacteria that cause outbreaks through the consumption of contaminated vegetables. The 
Centers for Diseases and Control and Prevention (CDC) revealed that many E. coli $\mathrm{O} 157: \mathrm{H} 7$ outbreaks were linked to contaminated vegetables, including romaine lettuce, leafy greens, alfalfa sprouts, salads and spinach (CDC, 2019). In September 2006, 205 people were infected with a virulent strain of $E$. coli $\mathrm{O} 157: \mathrm{H} 7$ in the United States of America (USA). Among the infected people, 103 individuals were hospitalised, 31 cases of hemolytic-uremic syndrome (HUS) and three deaths. The outbreak was related to the consumption of fresh bagged spinach (Seltzer et al., 2009).

Many cases of salmonellosis in human are related to the consumption of contaminated food products, especially those of animal origins such as eggs, beef, milk, poultry and pork. However, this disease has also been associated with fresh vegetables, and it has been recognised as a transmission vehicle for Salmonella (Bouchrif et al., 2009). For example, Salmonella has been found in alfalfa sprouts, cucumber, cilantro, celery, lettuce, tomato and parsley (Pui et al., 2011; Food and Drug Administration (FDA), 2016). In addition, several outbreaks of Salmonella attributed to contaminated fresh vegetables have been reported worldwide. In August 2014, an outbreak of Salmonella enterica ser. Newport caused by cucumber was identified in 29 states of the US and the district of Columbia. The outbreak resulted in 257 cases, 34\% were hospitalised, and one death was recorded (Angelo et al., 2015). Interestingly, Bahri et al. (2020) demonstrated that E. coli and Salmonella isolated from ulam were able to form biofilms and reveal the ability of these isolates to persist on the fresh produce and become hosts for the transmission of disease to humans or/and animals. In addition, the presence of antibiotic-resistant $E$. coli in raw vegetables may pose health threats to consumers and indicate the role of fresh produce as a reservoir of resistant pathogenic bacteria (Bahri et al., 2019).

Microbiological risk assessment is an indicator tool for the evaluation of the safety of food and water supplies used during food production. The presence of microorganisms indicates improper treatment or postdisinfection contamination (Chaturvedi et al., 2013). This study aimed to evaluate the microbiological quality of minimally processed ulam sold in wet markets and supermarkets in Kuala Terengganu, Malaysia. The incidence level of aerobic mesophilic bacteria, Salmonella spp., coliforms, Bacillus cereus, yeast and mould and Listeria monocytogenes were assessed from the ulam samples. Moreover, the presence of E. coli and Salmonella spp. were also detected in the samples analysed. Up to now, this is the first study on the microbiological quality of ulam sold in Kuala Terengganu, Malaysia.

\section{Material and methods}

\subsection{Microbiological quality of fresh raw ulam}

A total of 6 types of fresh ulam were selected for microbiological quality which consists of leafy vegetables and non-leafy vegetables. The leafy vegetables include pegaga (Centella asiatica), ulam raja (Cosmos caudatus) and selom (Oenanthe javanica). The non-leafy vegetables are bean sprout/tauge (Vigna radiata), winged bean (Psophocarpus tetragonolobus), and long bean (Vigna unguiculata) (Table 2).

\subsubsection{Experimental design}

The detailed experimental design used for the microbiological quality of fresh raw ulam in supermarkets and wet markets is described in Table 1.

\subsubsection{Method for microbiological quality}

A total of $25 \mathrm{~g}$ of each cut of fresh raw ulam (pegaga, ulam raja, selom, bean sprout/tauge, winged bean and long bean) were weighed into a sterile stomacher bag. Each type of ulam was transferred into 3 sterile stomacher bags to obtain triplicate results. The $225 \mathrm{~mL}$ of sterile buffered peptone water (BPW) (Merck, Germany) was added and then stomached for 2 mins using a stomacher (BagMixer 400, Interscience, Singapore) (Buyukunal et al., 2015). The homogenised solution was made a serial dilution until $10^{-7}$.

Table 1. The experimental design for microbiological quality

\begin{tabular}{|c|c|}
\hline Objective & To quantify the occurrence of Escherichia coli and Salmonella in ulam in Terengganu \\
\hline Number of samples & 6 samples of ulam \\
\hline Factor (Independent variable) & $\begin{array}{c}6 \text { samples of ulam collected from wet market and supermarket (selom, pegaga, ulam raja, } \\
\text { bean sprout, winged bean and long bean) }\end{array}$ \\
\hline Factor level (Treatment) & $\begin{array}{l}\text { F1: Plating samples on different types of selective media agar (PCA, MacConkey, XLD, } \\
\text { MYP, PALCAM, DRBC agar) } \\
\text { F2: Dilution from } 10^{-2} \text { until } 10^{-7}\end{array}$ \\
\hline Arrangement & Two-way arrangement \\
\hline Replication & 3 replications \\
\hline Experimental unit (EU) & $(6 \times 2$ types of market $) \times 3$ replications $=36 \mathrm{EU}$ \\
\hline Response (Dependent Variable) & Colony Forming units (CFU) \\
\hline Statistical Analysis & Independent t-test and Mann- Whitney Test \\
\hline
\end{tabular}


Table 2. Ulam samples examined in this study for microbiological quality

\begin{tabular}{cccccc}
\hline Local name & Scientific Name & English name & Supermarket & Wet Market & Total \\
\hline Pegaga & Centella asiatica & Indian pennywort & 1 & 1 & 2 \\
Ulam Raja & Cosmos caudatus & Wild parsley & 1 & 1 & 2 \\
Selom & Oenanthe javanica & Japanese parsley & 1 & 1 & 2 \\
Kacang Panjang & Vigna unguiculata & Long bean & 1 & 1 & 2 \\
Kacang Botol & Psophocarpus tetragonolobus & Winged bean & 1 & 1 & 2 \\
Tauge & Vigna radiata & Bean sprout & 1 & 1 & 2 \\
\hline Total & & 6 & 6 & 12 \\
\hline
\end{tabular}

For the total plate count, $100 \mu \mathrm{L}$ of the serial dilutions were inoculated on the Plate count agar (PCA) (Oxoid, UK). The inoculum was spread rapidly over the entire agar surface using a glass spreader. Prior, the glass spreader was sterilised by placing it in $95 \%$ ethanol and then flaming it until all the alcohol has evaporated. Then, the plates were incubated at $35^{\circ} \mathrm{C}$ for $24 \mathrm{hrs}$. After incubation, the number of colonies was counted and recorded (Da Silva et al., 2007).

For coliform count, the sample preparation was carried out as mentioned above. Then, $100 \mu \mathrm{L}$ of the prepared sample was spread plated on MacConkey agar (Oxoid, UK) and incubated at $35^{\circ} \mathrm{C}$ for $24 \mathrm{hrs}$. Total coliform counts on MacConkey agar were determined by counting the red or pink, round, medium-sized colonies. The number of typical colonies was recorded for each plate (Thunberg et al., 2002).

The method used for the enumeration of Bacillus cereus was described in the Bacteriological Analytical Manual (Tallent et al., 2019). Approximately $100 \mu \mathrm{L}$ of the prepared sample was spread plate on Mannitol Egg Yolk Polymyxin agar (MYP) agar (Oxoid, UK) with sterile glass spreader and incubated at $35^{\circ} \mathrm{C}$ for $24 \mathrm{hrs}$. $B$. cereus colonies are typically pink on MYP agar surrounded by a precipitate zone, indicating that lecithinase is produced. The typical colonies of B. cereus were counted and recorded.

Yeast and moulds counts were conducted by spread plate method on Dichloran Rose Bengal Chloramphenicol (DRBC) agar (Oxoid, UK). Approximately $100 \mu \mathrm{L}$ of each dilution was inoculated on DRBC agar and incubated at $25^{\circ} \mathrm{C}$. The colonies of yeast and moulds were counted and recorded after 3 and 5 days in plates containing up to 150 colonies to avoid overgrowth (ISO 21527-1, 2008). The average of the counts was from triplicate determinations, recorded and converted into $\log _{10} \mathrm{CFU} / \mathrm{g}$.

The method used for enumeration of Salmonella spp. is based on the Bacteriological Analytical Manual (Andrews et al., 2011). Each type of ulam was transferred into 3 sterile stomacher bags to obtain triplicate results. A total of $25 \mathrm{~g}$ of sample was homogenised with $225 \mathrm{~mL}$ of buffered peptone water
(BPW) (Merck, Germany) and incubated at $35^{\circ} \mathrm{C}$ for 24 hrs. Then, the culture was inoculated into Rappaport Vassiliadis soya peptone (RVS) broth (Oxoid, UK) and Tetrathionate (TT) broth (Merck, Germany) and incubated at $35^{\circ} \mathrm{C}$ for $24 \mathrm{hrs}$. After that, the culture was serially diluted until $10^{-7}$. Then, $100 \mu 1$ of each diluted sample was inoculated onto Xylose Lysine Desoxycholate (XLD) agar (Oxoid, UK) by spread plate method. Then, the plates were incubated at $35^{\circ} \mathrm{C}$ for 24 hrs. Salmonella spp. colonies usually grow as red colonies with a black centre. The typical colonies of Salmonella spp. were counted and recorded.

The method used for enumeration of Listeria monocytogenes is based on the United States Department of Agriculture (United States Department of AgricultureFood Safety And Inspection Service [USDA-FSIS], 2013). Each type of fresh raw ulam was transferred into 3 sterile stomacher bags to obtain triplicate results. A total of $25 \mathrm{~g}$ of sample was homogenised with $225 \mathrm{~mL}$ of sterile Listeria selective enrichment broth (UVM1) (Oxoid, UK) and stomached for 2 mins using a stomacher. The enrichment bag was incubated at $30^{\circ} \mathrm{C}$ for $24 \mathrm{hrs}$. Then, the culture was inoculated into Fraser Broth (Oxoid, UK) and incubated at $35^{\circ} \mathrm{C}$ for $24 \mathrm{hrs}$. After being incubated, the culture was serially diluted until $10^{-7}$. Then, $100 \mu \mathrm{L}$ of the diluted sample was inoculated onto PALCAM agar (Oxoid, UK) by the spread plate method and incubated at $35^{\circ} \mathrm{C}$ for $24 \mathrm{hrs}$. Listeria monocytogenes colonies grow as a grey-green coloured colony with a black zone. The typical colonies of Listeria monocytogenes were counted and recorded.

\subsection{Isolation and detection of Escherichia coli and Salmonella spp.}

\subsubsection{Sample selection}

A total of 32 samples of ulam were randomly purchased from wet markets and supermarkets based on their availability from 2016 to 2017 in Kuala Terengganu, Terengganu, Malaysia (Table 3). The fresh vegetables consisted of pegaga (Centella asiatica), ulam raja (Cosmos caudatus), ketumbar (Coriandrum sativum), kangkung (Ipomoea aquatica), daun sup/ parsley (Petroselinum crispum), Vietnamese coriander/ kesum (Persicaria odorata), lettuce/salad kampung (Lactuca sativa), pucuk putat (Barringtonia racemosa), 
Table 3. Ulam samples examined in this study for isolation of E. coli and Salmonella

\begin{tabular}{cccc}
\hline Local name & Scientific Name & English name & Total \\
\hline Pegaga & Centella asiatica & Indian pennywort & 4 \\
Tauge & Vigna radiata & Bean sprout & 4 \\
Kacang Panjang & Vigna unguiculata & Long bean & 4 \\
Ulam Raja & Cosmos caudatus & Wild cosmos & 3 \\
Kacang Botol & Psophocarpus tetragonolobus & Winged bean & 3 \\
Salad Kampung & Lactuca sativa & Lettuce & 2 \\
Daun Sup & Petroselinum crispum & Parsley & 2 \\
Cucumber & Cucumis sativus & Cucumber & 2 \\
Kangkung & Ipomoea aquatica & Water spinach & 2 \\
Selom & Oenanthe javanica & Japanese parsley & 2 \\
Kesum & Persicaria odorata & Vietnamese coriander & 1 \\
Ketumbar & Coriandrum sativum & Coriander & 1 \\
Bayam & Amaranthus & Spinach & 1 \\
Pucuk Putat & Barringtonia racemosa & Freshwater mangrove & 1 \\
\hline Total & & & 32
\end{tabular}

bean sprout/tauge (Vigna radiata), long bean/kacang panjang (Vigna unguiculata), winged bean/kacang botol (Psophocarpus tetragonolobus), selom (Oenanthe javanica), spinach/bayam (Amaranthus) and cucumber (Cucumis sativus).

\subsubsection{Sample preparation for isolation of Escherichia coli and Salmonella}

The samples were purchased fresh in the morning and placed in an icebox with ice packs. Then, they were transported to the laboratory immediately and processed within 2 hrs of collection. No additional washing steps were applied to the samples after collection as this would represent the actual microflora present in the ulam samples (Hassan and Purwani, 2016). Then, $25 \mathrm{~g}$ of each cut of fresh raw ulam were aseptically weighed in a sterile stomacher bag and homogenised with $225 \mathrm{ml}$ of sterile buffered peptone water (BPW) (Merck, Germany) for two minutes using a stomacher (BagMixer 400, Interscience, Singapore) (Buyukunal et al., 2015).

\subsubsection{Escherichia coli}

The isolation of E. coli was done by following the method described in the Bacteriological Analytical Manual (Feng et al., 2011). The culture from the stomaching bag containing BPW was inoculated onto MacConkey (Oxoid, UK), Violet Red Bile Agar (VRBA) (BD, France) and Eosin Methylene Blue (EMB) (Lab M, UK) agar using the streaking method. The plates were incubated at $35^{\circ} \mathrm{C}$ for $24 \mathrm{hrs}$ in an incubator (Memmert, Germany). Escherichia coli ATCC 25922 was used as a positive control and Staphylococcus aureus ATCC 25923 as a negative control.

\subsubsection{Salmonella spp.}

The isolation of Salmonella spp. was done by referring to the method based on the Bacteriological Analytical Manual (Andrews et al., 2011). The homogenised buffered peptone water (BPW) (Merck, Germany) were incubated at $35^{\circ} \mathrm{C}$ for $24 \mathrm{hrs}$. Then, the BPW culture was inoculated into Rappaport Vassiliadis soya peptone (RVS) broth (Oxoid, UK) and Tetrathionate (TT) broth (Merck, Germany). The broth was incubated at $35^{\circ} \mathrm{C}$ for $24 \mathrm{hrs}$. The culture from RVS and TT enrichment were then inoculated to Xylose Lysine Desoxycholate (XLD) agar, Bismuth Sulphite (BS) agar (Merck, Germany) and Hektoen Enteric (HE) agar (Merck, Germany) using the streaking method. Those plates were incubated at $35^{\circ} \mathrm{C}$ for $24 \mathrm{hrs}$ and examined for typical colonies. Salmonella ATCC 14028 was used as a positive control, and Enterococcus faecalis ATCC 29212 as a negative control.

\subsection{Biochemical test}

\subsubsection{Triple sugar iron (TSI) and lysine iron (LI)} agar test

The presumptive Salmonella spp. were selected and screened biochemically using triple sugar iron (TSI) agar (Oxoid, UK) or lysine iron (LI) agar (Merck, Germany) slopes in conjunction with urease and sucrose/lactose media. First, the colonies were inoculated on nutrient agar and incubated at $35^{\circ} \mathrm{C}$ for $24 \mathrm{hrs}$. The well-isolated colony was inoculated on the TSI and LI agar. The agar medium was first stabbed through the middle to the bottom of the tube then streaked along the surface of the agar slant. After that, the TSI and LI agar were incubated at $35^{\circ} \mathrm{C}$ for $24 \mathrm{hrs}$ (Acharya, 2013). The typical strains of Salmonella produce an acid (yellow) butt and an alkaline (red) slope in TSI agar and an alkaline (purple) reaction throughout the LI medium, both with blackening due to hydrogen sulphide production, are urease negative and do not ferment sucrose or lactose (Neogen Coorporation, 2017). The Salmonella ATCC 14028 were used as positive control and Enterobacter cloacae ATCC 23355 as a negative control. The negative control produces acid 
butt, alkaline slant and no production of hydrogen sulphide in LI agar.

\subsubsection{Gram staining}

The standard protocol of Gram staining was done by referring to the method described by Cappuccino and Sherman (2014). First, the bacterial smear was air-dried and heat-fixed on a slide. Then, the smear was flooded with crystal violet (Merck, Germany) for $1 \mathrm{~min}$ and rinsed with distilled water. After that, the smear was flooded with Gram's iodine ( $\mathrm{R}$ and M Chemicals, UK) for $1 \mathrm{~min}$, rinsed and decolourised by using $95 \%$ ethanol (R and M Chemicals, UK) for 5-10 s. Then, the smear was immediately rinsed with distilled water, flooded with safranin (Sigma Aldrich Inc., Germany) for $1 \mathrm{~min}$, rinsed with distilled water, blot dried and observed under oil immersion using a light microscope with a total magnification of 1000x (Leica DME, Matrix Optics (M) Sdn Bhd, Malaysia).

\subsubsection{Oxidase test}

A strip of filter paper was soaked with a little freshly made Kovacs oxidase reagent. Then, a large mass of pure culture was rubbed on it by using a toothpick. The filter paper was observed for $60 \mathrm{~s}$. The area of inoculation indicated a positive reaction turned from dark blue to almost black. If the colour changes did not occur, the result was considered a negative result (PHE, 2019). Members of the family Enterobacteriaceae such as E. coli and Salmonella were classified as oxidase negative.

\subsubsection{Analytical profile index (API20E)}

The API20E test was carried out according to Holmes et al. (1978). First, three-quarters of water was added to fill all the honeycombed wells of the tray. Then, a single isolated colony was selected and emulsified in an ampule of API $\mathrm{NaCl} 0.85 \%$ medium. The isolate was then transferred to the well by using a sterile pipette. For (CIT, VP and GEL tests), both tubes and cupules were filled with the isolate solution. While only the tubes were filled for the remaining tests. For (ADH, LDC, ODC, $\mathrm{H}_{2} \mathrm{~S}$ and URE) tests, the tubes were overlaid with mineral oil to achieve anaerobiosis. The strips were incubated at a temperature of $37^{\circ} \mathrm{C}$ for $18-24 \mathrm{hrs}$. After the incubation period, the strip was read by referring to the Reading Table. If three or more tests (GLU test + or ) were positive, the strip should require the addition of a reagent. One drop of TDA reagent was added to the TDA test. One drop of JAMES reagent was added to the IND test. One drop each of VP 1 and VP 2 was added to the VP test. After 10 mins, the colours against the chart were compared, and the API record sheet was recorded. If the number of positive results (including the GLU test) was less than 3, the strip was re-incubated for another 24 hrs without any reagent being added. The identification of unknown isolates was performed by using apiweb $^{\mathrm{TM}}$ identification software online.

\subsection{Statistical analysis}

Colony counts were converted into $\log _{10} \mathrm{CFU} / \mathrm{g}$. The data were analysed by an independent sample $t$-test to determine mean values, standard deviation, and any statistically significant difference among all samples from wet markets and supermarkets using IBM SPSS Statistic Version 20 (SPSS Inc. Chicago, USA).

\section{Results and discussion}

\subsection{Microbiological quality of fresh raw ulam}

A total of twelve samples of ulam were selected for this study, namely pegaga (Centella asiatica), ulam raja (Cosmos caudatus), selom (Oenanthe javanica), bean sprout/tange (Vigna radiata), winged bean (Psophocarpus tetragonolobus), and long bean (Vigna unguiculata). The samples were taken from two different types of markets which were wet markets and supermarkets. Overall, this study reveals that all twelve fresh raw ulam were contaminated with bacteria. The results present that the microbial load varied with the location of sampling and the type of ulam.

According to Nyenje et al. (2012), one of the microbiological indicators is the presence of aerobic mesophilic bacteria in food, and it reflects the exposure of the sample to any contamination. This parameter is useful to confirm if cleaning, disinfection and temperature control during processing, transportation and storage, have been carried out properly. Figure 1 shows the aerobic mesophilic count in the samples analysed, respectively. The mean aerobic mesophilic count for all tested samples was $7.38 \log _{10} \mathrm{CFU} / \mathrm{g}$, ranging from 6.36 to $8.83 \log _{10} \mathrm{CFU} / \mathrm{g}$ (Table 4). Similar to the present study, Mritunjay and Kumar (2017) reported that the majority of raw salad vegetables collected from the retail market in India were also in the range of 6.0 to $8.0 \log _{10}$ CFU/g. Another study by Abadias et al. (2008) which examined fresh-cut and whole vegetables from supermarkets in Spain also found similar high loads of aerobic mesophilic bacteria up to 8.9 and $8.0 \log _{10} \mathrm{CFU} /$ g, respectively. According to the Hazard Analysis and Critical Control Points-Total Quality Management (HACCP-TQM) Technical Guide, raw foods containing less than $4 \log _{10} \mathrm{CFU} / \mathrm{g}$, 4-6.69 $\log _{10} \mathrm{CFU} / \mathrm{g}, 6.69-7.69$ $\log _{10} \mathrm{CFU} / \mathrm{g}$ and more than $7.69 \log _{10} \mathrm{CFU} / \mathrm{g}$ (aerobic mesophilic count) are classified as good, average, poor and spoiled food, respectively (Aycicek et al., 2006). In this study, $42 \%$ of ulam samples were considered as spoiled food, whereas $42 \%$ as poor and $16 \%$ as average. 
Table 4. The distribution of contaminated samples according to the types of medium agar used

\begin{tabular}{ccccccccc}
\hline \multirow{2}{*}{ Microorganisms } & \multirow{2}{*}{$\begin{array}{c}\text { Number of } \\
\text { samples }\end{array}$} & \multicolumn{2}{c}{ Microbial $\operatorname{load}_{\left(\log _{10} \mathrm{CFU} / \mathrm{g}\right)}$} & \multicolumn{4}{c}{$\begin{array}{c}\text { Percentage of contaminated samples in the } \\
\text { indicated interval (\%) }\end{array}$} \\
\cline { 3 - 9 } & & Min & Max & Mean & $<3$ & $3-<6$ & $6-<9$ & $>9$ \\
\hline Aerobic mesophilic bacteria & 12 & 6.36 & 8.83 & 7.38 & 0 & 0 & $12(100)$ & 0 \\
Salmonella spp. & 12 & 0 & 8.16 & 4.3 & $5(42)$ & 0 & $7(58)$ & 0 \\
Coliforms & 12 & 4.14 & 7.48 & 6.02 & 0 & $5(42)$ & $7(58)$ & 0 \\
Bacillus cereus & 12 & 0 & 0 & 0 & 0 & 0 & 0 & 0 \\
Yeast and Molds & 12 & 3.94 & 6.45 & 5.42 & 0 & $8(67)$ & $4(33)$ & 0 \\
Listeria spp. & 12 & 0 & 0 & 0 & 0 & 0 & 0 & 0 \\
\hline
\end{tabular}

Aerobic mesophilic count

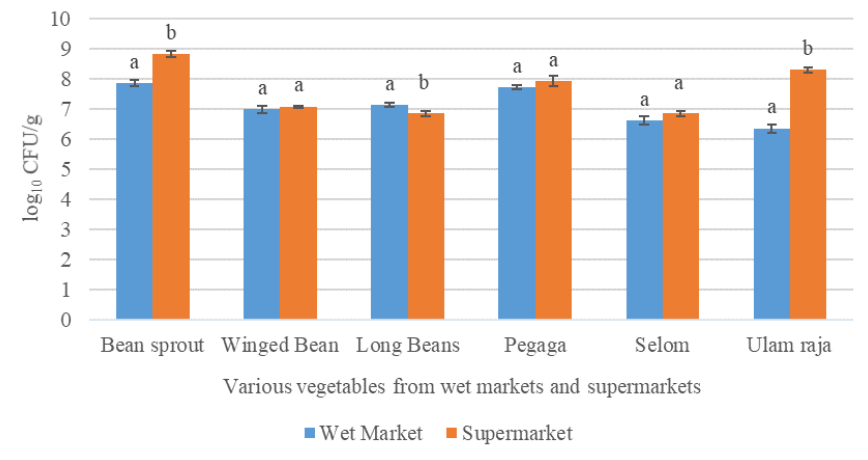

Figure 1. The aerobic mesophilic count of various vegetables from wet markets and supermarkets. Bars are mean \pm standard deviation of triplicates. Bars with different notations indicate significant difference $(p<0.05)$ between samples taken from supermarkets and wet markets.

The highest aerobic mesophilic plate count was observed in bean sprouts $\left(8.83 \pm 0.09 \log _{10} \mathrm{CFU} / \mathrm{g}\right)$ from supermarkets, followed by ulam raja $\left(8.31 \pm 0.09 \log _{10}\right.$ $\mathrm{CFU} / \mathrm{g})$ and pegaga $\left(7.93 \pm 0.17 \log _{10} \mathrm{CFU} / \mathrm{g}\right)$. Maximum TPC in wet markets was recorded in bean sprout (7.88 $\left.\pm 0.09 \log _{10} \mathrm{CFU} / \mathrm{g}\right)$ followed by pegaga $(7.73 \pm 0.07$ $\left.\log _{10} \quad \mathrm{CFU} / \mathrm{g}\right)$ whereas minimum for ulam raja $\left(6.36 \pm 0.14 \log _{10} \mathrm{CFU} / \mathrm{g}\right)$ and selom $\left(6.63 \pm 0.13 \log _{10}\right.$ $\mathrm{CFU} / \mathrm{g}$ ). These results are in line with Thunberg et al. (2002) who reported that the aerobic mesophilic count in sprouts at retail markets in Washington D.C. was 8.7 $\log _{10}$ CFU/g. Similarly, Abadias et al. (2008) conducted a survey on sprouts in Spain and found that the aerobic mesophilic bacteria was $7.9 \log _{10} \mathrm{CFU} / \mathrm{g}$. High microbial loads in bean sprouts might be due to the contaminated water and soil, improper handling and favourable conditions during germination such as suitable temperature, $\mathrm{pH}$, moisture and nutrients. Soaking bean sprouts overnight in water during the seed germination process was found to increase their aerobic microbial counts by ten folds (Seow et al., 2012).

T-tests were used to analyse the significant difference between two markets, supermarket and wet market. Statistically, the colony count of aerobic mesophilic bacteria of bean sprout and ulam raja purchased from the supermarket were significantly higher than the wet market $(p<0.05)$. Interestingly, the bacterial count of long beans purchased from the wet market was significantly higher than the supermarket ( $\mathrm{p}$ $<0.05$ ). However, no significant of these two markets was observed for winged bean and selom samples $(\mathrm{p}>$ $0.05)$.

Coliforms are common inhabitants of animal and human guts and are considered to be a hygiene indicator, especially for faecal contamination (Chaturvedi et al., 2013; Mritunjay and Kumar, 2017). In this study, the mean coliform counts for all ulam samples was 6.02 $\log _{10} \mathrm{CFU} / \mathrm{g}$, ranging from 4.14 to $7.48 \log _{10} \mathrm{CFU} / \mathrm{g}$ (Table 4). These results are in agreement with Mritunjay and Kumar (2017), where all raw salad vegetables collected in India had coliform counts from 3.0 to 7.8 $\log _{10} \mathrm{CFU} / \mathrm{g}$. According to Food Standards Australia New Zealand (2016), total coliforms in ready-to-eat food was categorised as unsatisfactory if higher than $4.0 \log _{10}$ $\mathrm{CFU} / \mathrm{g}$. Surprisingly, these results revealed that all ulam purchased from both wet market and supermarket surpassed the limits for the total coliform count, signifying the raw vegetables were not fit to be eaten.

As presented in Figure 2, the highest coliform counts in supermarkets were observed in bean sprout $(7.48 \pm 0.09$ $\left.\log _{10} \mathrm{CFU} / \mathrm{g}\right)$, followed by ulam raja $\left(7.11 \pm 0.03 \log _{10}\right.$ $\mathrm{CFU} / \mathrm{g})$ and pegaga $\left(6.46 \pm 0.38 \log _{10} \mathrm{CFU} / \mathrm{g}\right)$. For wet markets, the highest coliform counts were recorded in the bean sprout $\left(6.96 \pm 0.04 \log _{10} \mathrm{CFU} / \mathrm{g}\right)$, followed by pegaga $\left(6.40 \pm 0.16 \log _{10} \mathrm{CFU} / \mathrm{g}\right)$ and selom $(5.47 \pm 0.05$ $\left.\log _{10} \mathrm{CFU} / \mathrm{g}\right)$. The microorganism was also detected in the long bean, winged bean and ulam raja. These results are similar to the previous study, where most of the leafy vegetables showed coliform counts of more than 4.0 $\log _{10}$ CFU/g. Sair et al. (2017) reported that lettuce from local distributors and retailers in Pakistan had a high coliform count of $6.2 \log _{10} \mathrm{CFU} / \mathrm{g}$. Another study conducted by Mritunjay and Kumar (2017) also found that the coliform counts in spinach and coriander from the retail market in India were 5.8 and $4.7 \log _{10} \mathrm{CFU} / \mathrm{g}$, respectively. The possible explanation related to high coliform counts in leafy vegetables is that they have open leaves with large surface areas and folds. These open leaves often touch the soil and irrigation water, making them more vulnerable to bacterial 
contaminations and adhesion (Seow et al., 2012; Mritunjay and Kumar, 2017).

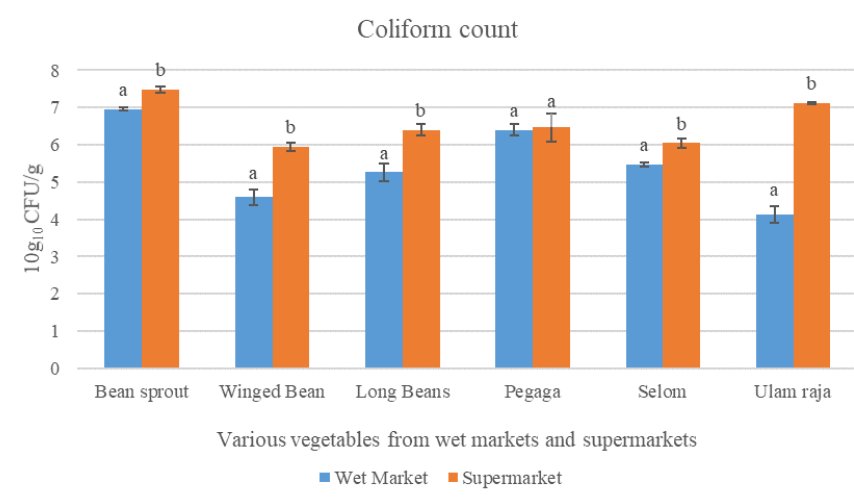

Figure 2. Total coliform count of various vegetables from wet markets and supermarkets. Bars are mean \pm standard deviation of triplicates. Bars with different notations indicate significant difference $(p<0.05)$ between samples taken from supermarkets and wet markets.

There is a significant difference in the number of total coliforms between wet markets and supermarkets. Total coliforms count in bean sprout, winged bean, long bean, selom and ulam raja from supermarkets were significantly higher compared to wet market $(\mathrm{p}<0.05)$. No significant difference was found in pegaga isolated from the wet market and supermarket $(\mathrm{p}>0.05)$.

Figure 3 present the results of Salmonella spp. counts of all ulam samples analysed. In this analysis, the level of Salmonella spp. in all ulam samples ranged from 0 to $8.16 \log _{10} \mathrm{CFU} / \mathrm{g}$, with a mean of $4.30 \log _{10} \mathrm{CFU} / \mathrm{g}$. The Salmonella spp. counts in the present study were relatively higher than in previous research. Hassan and Purwani (2016) reported that Salmonella spp. counts for fresh vegetables in West Java, Indonesia ranged from 1.30 to $3.95 \log _{10} \mathrm{CFU} / \mathrm{g}$. Similarly, Abakari et al. (2018) assessed the microbial quality of salad samples (cabbage, lettuce, onions and tomato) in Tamale, Ghana and found a lower Salmonella spp. counts ranged from 0 to $4.54 \log _{10} \mathrm{CFU} / \mathrm{g}$. According to Food Standards Australia New Zealand (2016) and NSW Food Authority (2009), the Salmonella spp. should not be detected in 25 $\mathrm{g}$ ready to eat foods for human consumption otherwise it should be categorized as potentially hazardous. Based on these guidelines, $58.3 \%$ of ulam samples were identified as unsatisfactory for human consumption.

In the supermarket, the contamination of Salmonella spp. was observed to be higher in leafy vegetables than in non-leafy vegetables. Among the leafy vegetables, selom $\left(8.16 \pm 0.13 \log _{10} \mathrm{CFU} / \mathrm{g}\right)$ had the highest colony count, followed by pegaga $\left(8.01 \pm 0.12 \log _{10} \mathrm{CFU} / \mathrm{g}\right)$ and ulam raja $\left(7.85 \pm 0.24 \log _{10} \mathrm{CFU} / \mathrm{g}\right)$. These results further support the statement of FAO/WHO (2008), which ranked leafy green vegetables as the highest level priority in terms of fresh produce safety and has been linked to high numbers of diseases. The Salmonella spp. can contaminate leafy vegetables at any stage of the production process, but large numbers of multistate outbreaks suggest that contamination occurred early in production. The leafy vegetables can be contaminated through animal manure used for fertilisers, irrigation water, and feral animals that invaded the vegetable fields (Herman et al., 2015). For the wet market, Salmonella spp. were not detected in mostly raw vegetables and only present in long bean $\left(6.71 \pm 0.08 \log _{10} \mathrm{CFU} / \mathrm{g}\right)$.

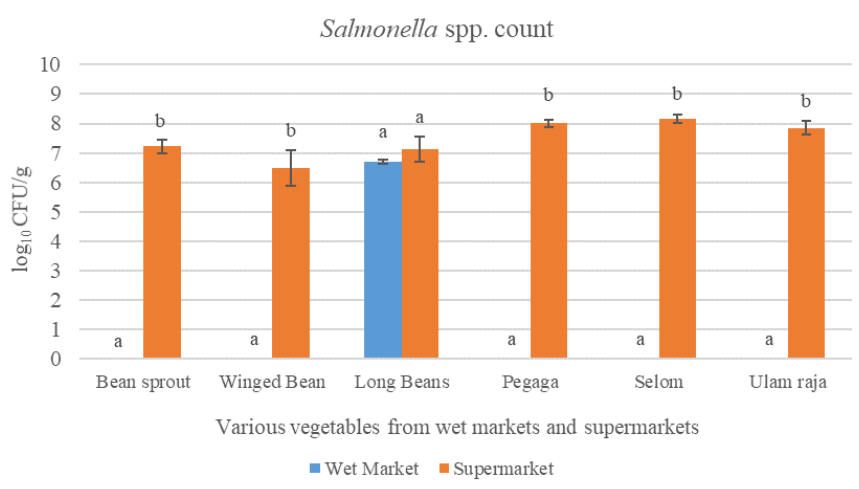

Figure 3. Salmonella spp. count of various vegetables from wet markets and supermarkets. Bars with different notations indicate significant difference $(\mathrm{p}<0.05)$ between samples taken from supermarkets and wet markets.

The data highlighted that the colony count of Salmonella spp. in bean sprout, winged bean, pegaga, selom and ulam raja from supermarkets was significantly higher compared to wet markets $(\mathrm{p}<0.05)$. There are several explanations attributed to the contamination, such as a longer holding time (the period between harvesting and selling) of ulam in the supermarket, thus giving more time for microorganisms to grow and multiply. During the raw vegetables selection process, unhygienic handling practices by the customers at the display unit will result in crosscontamination in the supermarket. Moreover, plastic containers used for storage and transportation of fresh produce may contribute to cross-contamination and foodborne infection (Hassan and Purwani, 2016). However, no significant difference was examined between the wet market and supermarket with regard to long bean samples $(\mathrm{p}>0.05)$.

The results of yeast and mould counts are shown in Figure 4. In this study, the ulam samples had a mean yeast and mould count of $5.42 \log _{10} \mathrm{CFU} / \mathrm{g}$, ranging from 3.94 to $6.45 \log _{10} \mathrm{CFU} / \mathrm{g}$. The mean value for yeast and moulds in all ulam samples is lower than aerobic mesophilic bacteria. Similar to the present study, Najafi and Bahreini (2012) reported that the mean count of yeast and mould for mixed fresh-cut vegetable salads was $5.68 \log _{10} \mathrm{CFU} / \mathrm{g}$, ranging from 3.85 to $6.7 \log _{10}$ 
$\mathrm{CFU} / \mathrm{g}$. Abadias et al. (2008) revealed that the yeast and mould count for fresh-cut vegetables was $5.2 \log _{10} \mathrm{CFU} /$ $\mathrm{g}$, with a range of 2.0 to $7.8 \log _{10} \mathrm{CFU} / \mathrm{g}$. These findings are further supported by a study conducted in Malaysia. Kuan et al. (2017) reported that the yeast and mould counts of most organic and conventional vegetables varied from 3 to $6 \log _{10} \mathrm{CFU} / \mathrm{g}$. According to James et al. (2019), the contamination of vegetables occurs because they have high moisture content, and fungi usually grow well under this condition. The presence of moulds in vegetables may pose a health risk to the consumer, as some of them may produce harmful mycotoxins or cause allergic reactions (Mritunjay and Kumar, 2017).

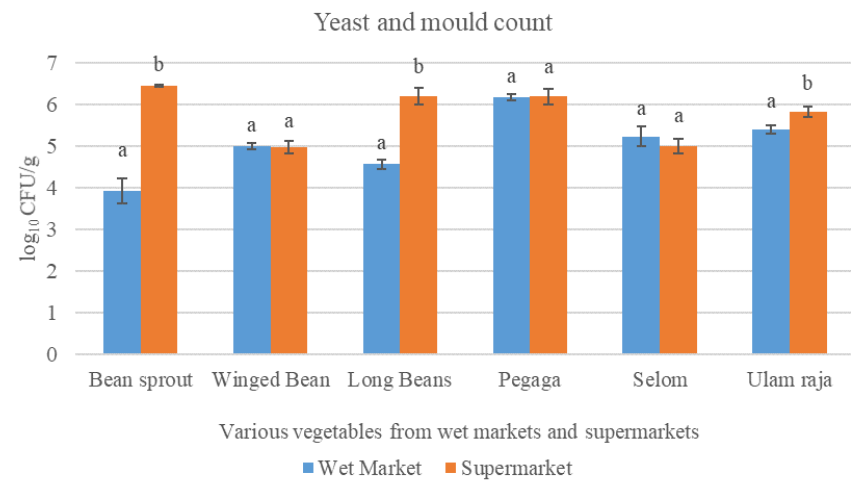

Figure 4. Yeast and moulds of various vegetables from wet markets and supermarkets. Bars with different notations indicate significant difference $(\mathrm{p}<0.05)$ between samples taken from supermarkets and wet markets.

The highest number of yeast and mould in ulam purchased from the supermarkets was recorded for bean sprout $\left(6.45 \pm 0.03 \log _{10} \mathrm{CFU} / \mathrm{g}\right)$, followed by long bean $\left(6.20 \pm 0.20 \log _{10} \mathrm{CFU} / \mathrm{g}\right)$ and pegaga (6.20 $\pm 0.19 \log _{10}$ $\mathrm{CFU} / \mathrm{g})$. These results are in agreement with Jeddi et al. (2014), who found that the yeast and mould count in mung bean and wheat sprout were 6.9 and $6.8 \log _{10}$ $\mathrm{CFU} / \mathrm{g}$, respectively. Further analysis demonstrated that the highest number of yeast and mould in ulam obtained from the wet market was reported for pegaga $(6.18 \pm 0.07$ $\left.\log _{10} \mathrm{CFU} / \mathrm{g}\right)$, followed by ulam raja $\left(5.41 \pm 0.09 \log _{10}\right.$ $\mathrm{CFU} / \mathrm{g})$, selom $\left(5.24 \pm 0.23 \log _{10} \mathrm{CFU} / \mathrm{g}\right)$ and winged bean $\left(5.01 \pm 0.08 \quad \log _{10} \quad \mathrm{CFU} / \mathrm{g}\right)$. These findings are consistent with Kuan et al. (2017), who detected yeast and mould in the levels of $5.61 \log _{10} \mathrm{CFU} / \mathrm{g}$. in winged bean. The minimum colony count of yeast and mould purchased from the wet market was detected in bean sprout $\left(3.94 \pm 0.30 \log _{10} \mathrm{CFU} / \mathrm{g}\right)$, followed by long bean $\left(4.57 \pm 0.11 \log _{10} \mathrm{CFU} / \mathrm{g}\right)$. From Figure 4 , it can be seen that the colony count of yeast and moulds in bean sprout, long bean and ulam raja purchased from the supermarket was significantly higher than the wet market $(\mathrm{p}<0.05)$. No significant difference was observed between the supermarket and wet market with respect to winged bean, pegaga and selom ( $\mathrm{p}>0.05)$.

Interestingly, there was no evidence of Bacillus cereus in any of the ulam samples. This finding is consistent with other previous studies. For example, Nguz et al. (2005) conducted a survey on fresh organic mixed vegetables and green beans obtained in Zambia and these samples were found to be free of B. cereus. This is maybe attributed to postharvest treatments such as washing and disinfection that are effective in killing pathogenic bacteria (Thunberg et al., 2002). In contrast to earlier studies, Kim et al. (2016) reported a high incidence of $B$. cereus in organic $(70 \%)$ and conventional $(30 \%)$ vegetables purchased from the retail market in South Korea. Moreover, six samples of organic vegetables had a high level of $B$. cereus over $4 \log _{10}$ $\mathrm{CFU} / \mathrm{g}$, which is considered to be unsatisfactory. In China, $50 \%$ of vegetable samples (coriander, lettuce, cucumber and tomato) were contaminated with $B$. cereus.

In this study, Listeria monocytogenes was not detected in any ulam samples analysed. Similarly, the $L$. monocytogenes was absent in a survey conducted on fresh vegetables in Istanbul, Turkey (Buyukunal et al., 2015). However, these findings differ from Ponniah et al. (2010), who surveyed the occurrence of $L$. monocytogenes in raw vegetables (carrot, sweet potatoes, Indian pennywort, cabbage, Japanese parsley, wild parsley, winged bean, yardlong bean, tomato and cucumber) purchased from markets in Selangor, Malaysia. They found that $22.5 \%$ of the raw vegetables were contaminated with L. monocytogenes. Moreover, Sant'Ana et al. (2012) reported that L. monocytogenes was found in $3.1 \%$ of ready-to-eat vegetables sold in Sao Paulo, Brazil. In their study, L. monocytogenes was detected in five samples, which ranged from 1 to 2.41 $\log _{10} \mathrm{CFU} / \mathrm{g}$. Although L. monocytogenes was absent in this study, the humid and warm environment may favourable the growth of L. monocytogenes in fresh vegetables (Kuan et al., 2017). Therefore, it is essential to continuously monitor the prevalence of $L$. monocytogenes sold in our market.

\subsection{Isolation and biochemical test of Escherichia coli}

A total of 87 presumptive $E$. coli were isolated after incubation in the selective media. E. coli colonies growing on Violet Red Bile Agar (VRBA) were appeared pink to red colonies with a red precipitate around colonies. While for MacConkey agar, E. coli was seemed to be pink to red with bile salt precipitate surrounding colonies. The E. coli colonies appeared blue -black centred colonies with green metallic sheen when grown on Eosin Methylene Blue (EMB) agar. Those 
isolates were further subjected to the pre-identification test, which includes Gram staining, oxidase test and API20E.

Gram staining is a common technique used to distinguish bacteria into two large groups of bacteria (Gram-positive and Gram-negative bacteria) based on their cell wall compositions. Members of the family Enterobacteriaceae such as E. coli and Salmonella were grouped in Gram-negative rod-shaped bacteria (Wardani et al., 2019). Moreover, the oxidase test was performed on the E. coli isolates. The oxidase test is used to determine bacteria that contain cytochrome c oxidase, a large transmembrane protein complex in the respiratory electron transport chain. If present, the cytochrome c oxidase would oxidize the reagent to dark blue, then the result is positive. However, if no colour changes occurred within three minutes, the result is considered to be negative. This test is helpful in screening colonies of suspected Enterobacteriaceae since they are generally lacking this enzyme and characterized as oxidase negative (Acharya, 2012). As shown in Table 5, only 23 E. coli isolates were classified as Gram-negative rodshaped bacteria and oxidase negative.

The presumptive isolates (23) were further tested with the API20E, and all of them were identified as $E$. coli (Table 6). Table 7 represents the incidence of $E$. coli in the 32 vegetable samples. In this study, E. coli was detected in $31.3 \%$ of samples (pegaga, bean sprout, ulam raja, salad kampung, daun sup, kangkung, kesum, ketumbar and pucuk putat). This result is in agreement with Hassan and Purwani (2016), which reported the incidence level of $E$. coli in fresh vegetables was $34 \%$. Similarly, in Pakistan, E. coli was found in $30.1 \%$ of vegetable samples (Sair et al., 2017). In this study, the incidence of $E$. coli isolates was higher than that found in previous reports. In India, Mritunjay and Kumar (2017) reported that E. coli was found in $16.7 \%$ of raw salad vegetables collected from the local and retail market. In addition, Abadias et al. (2008) also reported that 11.4\% of fresh-cut vegetables contained E. coli. The E. coli was observed in arugula, lettuce, spinach, and mixed salad sold in Spain. The levels of E. coli is used as an indicator of faecal contamination and to monitor the sanitary conditions of food (Nguz et al., 2005; Mritunjay and Kumar, 2017). Table 8 shows the distribution of $E$. coli varied with the types of vegetables. Among them, the $E$. coli isolates were found to be predominant on ketumbar $(\mathrm{n}=5)$, followed by kangkung $(\mathrm{n}=4)$, salad kampung $(\mathrm{n}$ $=4)$ and daun sup $(\mathrm{n}=4)$. No E. coli was detected in long bean, winged bean, cucumber and selom.

\subsection{Isolation and biochemical test of Salmonella spp.}

A total of 118 presumptive Salmonella were isolated after incubation in selective media. Salmonella colonies growing on XLD agar appeared red colonies with black centres. While for BS agar, Salmonella colonies seemed to be black or greenish-grey may or may not have a

Table 5. The results of Gram staining and oxidase test for presumptive E. coli

\begin{tabular}{|c|c|c|c|c|}
\hline Market & Sample & Coding & Gram Staining & Oxidase Test \\
\hline \multirow{6}{*}{ Wet Market } & Daun Sup & WMDS & Negative & Negative \\
\hline & \multirow{4}{*}{ Salad Kampung } & WMSK1 & Negative & Negative \\
\hline & & WMSK4 & Negative & Negative \\
\hline & & WMSK6 & Negative & Negative \\
\hline & & WMSK7 & Negative & Negative \\
\hline & Pucuk Putat & WMPP2 & Negative & Negative \\
\hline \multirow{17}{*}{ Supermarket } & Pegaga & SMP1 & Negative & Negative \\
\hline & \multirow{3}{*}{ Daun Sup } & SMDS1 & Negative & Negative \\
\hline & & SMDS2 & Negative & Negative \\
\hline & & SMDS4 & Negative & Negative \\
\hline & \multirow{4}{*}{ Kangkung } & SMKG1 & Negative & Negative \\
\hline & & SMKG2 & Negative & Negative \\
\hline & & SMKG3 & Negative & Negative \\
\hline & & SMKG4 & Negative & Negative \\
\hline & \multirow{5}{*}{ Ketumbar } & SMKB2 & Negative & Negative \\
\hline & & SMKB3 & Negative & Negative \\
\hline & & SMKB4 & Negative & Negative \\
\hline & & SMKB5 & Negative & Negative \\
\hline & & SMKB8 & Negative & Negative \\
\hline & \multirow{2}{*}{ Kesum } & SMK2 & Negative & Negative \\
\hline & & SMK3 & Negative & Negative \\
\hline & Ulam Raja & SMU2 & Negative & Negative \\
\hline & Bean Sprout/Tauge & SMT4 & Negative & Negative \\
\hline
\end{tabular}


Table 6. The results of confirmation of E. coli by API20E

\begin{tabular}{|c|c|c|c|c|}
\hline Market & Sample & Coding & Confirmation (API20E) & No. ID \\
\hline \multirow{6}{*}{ Wet Market } & Daun Sup & WMDS & Escherichia coli & 5144572 \\
\hline & \multirow{4}{*}{ Salad Kampung } & WMSK1 & Escherichia coli & 5044552 \\
\hline & & WMSK4 & Escherichia coli & 5144572 \\
\hline & & WMSK6 & Escherichia coli & 5144572 \\
\hline & & WMSK 7 & Escherichia coli & 5044552 \\
\hline & Pucuk Putat & WMPP2 & Escherichia coli & 5144572 \\
\hline \multirow{17}{*}{ Supermarket } & Pegaga & SMP1 & Escherichia coli & 5144552 \\
\hline & \multirow{3}{*}{ Daun Sup } & SMDS1 & Escherichia coli & 5144572 \\
\hline & & SMDS2 & Escherichia coli & 5144552 \\
\hline & & SMDS4 & Escherichia coli & 5144552 \\
\hline & \multirow{4}{*}{ Kangkung } & SMKG1 & Escherichia coli & 5144572 \\
\hline & & SMKG2 & Escherichia coli & 5144572 \\
\hline & & SMKG3 & Escherichia coli & 5144572 \\
\hline & & SMKG4 & Escherichia coli & 5144572 \\
\hline & \multirow{5}{*}{ Ketumbar } & SMKB2 & Escherichia coli & 5044572 \\
\hline & & SMKB3 & Escherichia coli & 5044572 \\
\hline & & SMKB4 & Escherichia coli & 5044572 \\
\hline & & SMKB5 & Escherichia coli & 5044552 \\
\hline & & SMKB8 & Escherichia coli & 5044572 \\
\hline & \multirow{2}{*}{ Kesum } & SMK2 & Escherichia coli & 5544572 \\
\hline & & SMK3 & Escherichia coli & 5544572 \\
\hline & Ulam Raja & SMU2 & Escherichia coli & 5544572 \\
\hline & Bean Sprout/Tauge & SMT4 & Escherichia coli & 5144572 \\
\hline
\end{tabular}

Table 7. The incidence of positive samples for E. coli and Salmonella in vegetables samples

\begin{tabular}{cccc}
\hline \multirow{2}{*}{ Vegetables } & $\mathrm{n}$ & \multicolumn{2}{c}{ Percentage (\%) of positive samples } \\
\cline { 3 - 4 } & & E. coli & Salmonella \\
\hline Pegaga & 4 & 1 & $\mathrm{ND}$ \\
Bean sprout/Tauge & 4 & 1 & 1 \\
Long bean/Kacang Panjang & 4 & $\mathrm{ND}^{\mathrm{a}}$ & 1 \\
Ulam Raja & 3 & 1 & $\mathrm{ND}$ \\
Winged bean/Kacang Botol & 3 & $\mathrm{ND}$ & $\mathrm{ND}$ \\
Salad Kampung & 2 & 1 & $\mathrm{ND}$ \\
Daun Sup & 2 & 2 & $\mathrm{ND}$ \\
Cucumber & 2 & $\mathrm{ND}$ & $\mathrm{ND}$ \\
Kangkung & 2 & 1 & $\mathrm{ND}$ \\
Selom & 2 & $\mathrm{ND}$ & 1 \\
Kesum & 1 & 1 & $\mathrm{ND}$ \\
Ketumbar & 1 & 1 & $\mathrm{ND}$ \\
Bayam & 1 & $\mathrm{ND}$ & $\mathrm{ND}$ \\
Pucuk Putat & 1 & 1 & ND \\
Total & 32 & $10 / 32(31.3)$ & $3 / 32(9.4 \%)$ \\
\hline
\end{tabular}

${ }^{\text {a }}$ ND: not detected

sheen. Colonies were appeared blue-green with or without black centres when grown on HE agar. Those isolates were further subjected to the pre-identification test, which includes triple sugar iron (TSI) and lysine iron (LI) agar test, Gram staining, oxidase test and API20E.

Table 9 shows that only 25 presumptive Salmonella spp. isolates showed positive results on TSI agar. The
Salmonella spp. isolates produced an alkaline (red) slope and acid (yellow) butt with blackening due to hydrogen sulphide production (Neogen Coorporation, 2017). The Salmonella spp. isolates were further subjected to Gram staining and oxidase test. All of the Salmonella spp. isolates were classified as Gram-negative rod-shaped and oxidase negative (Table 10). 
Table 8 . The distribution of $23 \mathrm{E}$. coli isolates by type of samples and location

\begin{tabular}{cccc}
\hline Location & Types of sample & Total number of isolates (\%) & Isolates coding \\
\hline \multirow{5}{*}{ Supermarkets } & Ketumbar & $5(21.74)$ & SMKB2, SMKB3, SMKB4, SMKB5, SMKB8 \\
\cline { 2 - 4 } & Kangkung & $4(17.39)$ & SMKG1, SMKG2,SMKG3, SMKG4 \\
\cline { 2 - 4 } & Kesum & $2(8.69)$ & SMK2, SMK3 \\
\cline { 2 - 4 } & Daun Sup & $3(13.04)$ & SMDS1, SMDS2, SMDS4 \\
\cline { 2 - 4 } & Pegaga & $1(4.35)$ & SMP1 \\
\cline { 2 - 4 } & Blam Raja & $1(4.35)$ & SMU2 \\
\hline \multirow{3}{*}{ Wean sprout/Tauge } & $1(4.35)$ & SMT4 \\
\cline { 2 - 4 } & Salad Kampung & $4(17.39)$ & WMSK1, WMSK4, WMSK6, WMSK7 \\
\cline { 2 - 4 } & Daun Sup & $1(4.35)$ & WMPP2 \\
\hline Total & Pucuk Putat & $1(4.35)$ & \\
\hline
\end{tabular}

Table 9. The results of triple sugar iron (TSI) test of presumptive Salmonella spp.

\begin{tabular}{|c|c|c|c|c|c|}
\hline Market & Sample & Coding & Butt & Slant Surface & $\mathrm{H}_{2}$ \\
\hline \multirow{7}{*}{ Wet Market } & Salmonella ATCC 14028 & $+\mathrm{SM}$ & Yellow+Black & Red & + \\
\hline & Pegaga & WMP.BS.TT 2 & Yellow+Black & Yellow & + \\
\hline & \multirow{2}{*}{ Selom } & WMS.HE.TT 2 & Yellow+Black & Red & + \\
\hline & & WMS.HE.TT 3 & Yellow+Black & Red & + \\
\hline & \multirow{3}{*}{ Long Bean/Kacang Panjang } & WKP.XLD 2 & Yellow+Black & Red & + \\
\hline & & WKP.XLD.RVS 1 & Yellow+Black & Red & + \\
\hline & & WKP.HE.TT 1 & Yellow+Black & Red & + \\
\hline \multirow{19}{*}{ Supermarket } & \multirow{4}{*}{ Ulam Raja } & SUR.XLD 1 & Yellow+Black & Red & + \\
\hline & & SUR.XLD 3 & Yellow+Black & Red & + \\
\hline & & SUR.XLD 9 & Yellow+Black & Red & + \\
\hline & & SUR.XLD 10 & Yellow+Black & Red & + \\
\hline & \multirow{4}{*}{ Pegaga } & SP.XLD 3 & Yellow+Black & Red & + \\
\hline & & SP.XLD 4 & Yellow+Black & Red & + \\
\hline & & SP.XLD 5 & Yellow+Black & Red & + \\
\hline & & SP.XLD 6 & Yellow+Black & Red & + \\
\hline & \multirow{3}{*}{ Long Bean/Kacang Panjang } & SMKP.XLD 1 & Yellow+Black & Red & + \\
\hline & & SMKP.XLD 3 & Yellow+Black & Red & + \\
\hline & & SMKP.XLD 4 & Yellow+Black & Red & + \\
\hline & \multirow{4}{*}{ Bean sprout/Tauge } & SMT.XLD 1 & Yellow+Black & Red & + \\
\hline & & SMT.XLD 2 & Yellow+Black & Red & + \\
\hline & & SMT.XLD 3 & Yellow+Black & Red & + \\
\hline & & SMT.XLD.RVS 1 & Yellow+Black & Red & + \\
\hline & \multirow{4}{*}{ Selom } & SMS.XLD 1 & Yellow+Black & Red & + \\
\hline & & SMS.XLD 2 & Yellow+Black & Red & + \\
\hline & & SMS.XLD 4 & Yellow+Black & Red & + \\
\hline & & SMS.XLD 5 & Yellow+Black & Red & + \\
\hline
\end{tabular}

As presented in Table 11, all of the presumptive that $0.2 \%$ of ready-to-eat salad vegetables were Salmonella spp. isolates were identified using API20E. Out of 25 isolates, only six showed a high percentage of similarity (99\%) to Salmonella enterica ser. Arizonae. In this study, $9.4 \%$ of samples were found contaminated with Salmonella spp (Table 7). The incidence of Salmonella in this study is low compared to previous results from Selangor. Salleh et al. (2003) reported that Salmonella spp. was detected in $35 \%$ of vegetable samples collected from wet markets. However, another study conducted in the United Kingdom showed a lower incidence of Salmonella (Sagoo et al., 2003). They found contaminated with Salmonella. Abadias et al. (2008) also reported that $1.3 \%$ of fruits and vegetable samples contained Salmonella spp. The Salmonella spp. was isolated from corn salad, lettuce, spinach and mixed salad. Table 12 presents the distribution of Salmonella spp. in the samples analyzed. The Salmonella spp. was only detected in three samples, which include bean sprout, selom and long bean. Most of the Salmonella spp. were isolated from bean sprout (four out of six isolates), while only one Salmonella spp. was found in selom and long bean. In contrast to this finding, no Salmonella spp. 
Table 10. The results of Gram staining and oxidase test for presumptive Salmonella spp.

\begin{tabular}{|c|c|c|c|c|}
\hline Market & Sample & Coding & Gram Staining & Oxidase Test \\
\hline \multirow{6}{*}{ Wet Market } & Pegaga & WMP.BS.TT 2 & Negative & Negative \\
\hline & \multirow{2}{*}{ Selom } & WMS.HE.TT 2 & Negative & Negative \\
\hline & & WMS.HE.TT 3 & Negative & Negative \\
\hline & \multirow{3}{*}{ Long Bean/Kacang Panjang } & WKP.XLD 2 & Negative & Negative \\
\hline & & WKP.XLD.RVS 1 & Negative & Negative \\
\hline & & WKP.HE.TT 1 & Negative & Negative \\
\hline \multirow{19}{*}{ Supermarket } & \multirow{4}{*}{ Ulam Raja } & SUR.XLD 1 & Negative & Negative \\
\hline & & SUR.XLD 3 & Negative & Negative \\
\hline & & SUR.XLD 9 & Negative & Negative \\
\hline & & SUR.XLD 10 & Negative & Negative \\
\hline & \multirow{4}{*}{ Pegaga } & SP.XLD 3 & Negative & Negative \\
\hline & & SP.XLD 4 & Negative & Negative \\
\hline & & SP.XLD 5 & Negative & Negative \\
\hline & & SP.XLD 6 & Negative & Negative \\
\hline & \multirow{3}{*}{ Long Bean/Kacang Panjang } & SMKP.XLD 1 & Negative & Negative \\
\hline & & SMKP.XLD 3 & Negative & Negative \\
\hline & & SMKP.XLD 4 & Negative & Negative \\
\hline & \multirow{4}{*}{ Bean sprout/Tauge } & SMT.XLD 1 & Negative & Negative \\
\hline & & SMT.XLD 2 & Negative & Negative \\
\hline & & SMT.XLD 3 & Negative & Negative \\
\hline & & SMT.XLD.RVS 1 & Negative & Negative \\
\hline & \multirow{4}{*}{ Selom } & SMS.XLD 1 & Negative & Negative \\
\hline & & SMS.XLD 2 & Negative & Negative \\
\hline & & SMS.XLD 4 & Negative & Negative \\
\hline & & SMS.XLD 5 & Negative & Negative \\
\hline
\end{tabular}

Table 11. The results of confirmation of Salmonella spp. by API20E

\begin{tabular}{|c|c|c|c|c|}
\hline Market & Sample & Coding & Confirmation (API20E) & No. ID \\
\hline \multirow{6}{*}{ Wet Market } & Pegaga & WMP.BS.TT 2 & 93.6\% Citrobacter freundii & 1604532 \\
\hline & \multirow{2}{*}{ Selom } & WMS.HE.TT 2 & 99.8\% Salmonella enterica ssp Arizonae & 7705512 \\
\hline & & WMS.HE.TT 3 & $99.8 \%$ Citrobacter youngae & 3604513 \\
\hline & \multirow{3}{*}{$\begin{array}{c}\text { Long Bean } / \text { Kacang } \\
\text { Panjang }\end{array}$} & WKP.XLD 2 & 99.8\% Citrobacter youngae & 3604512 \\
\hline & & WKP.XLD.RVS 1 & 99.8\% Citrobacter youngae & 3604512 \\
\hline & & WKP.HE.TT 1 & 99.8\% Citrobacter youngae & 3604512 \\
\hline \multirow{19}{*}{ Supermarket } & \multirow{4}{*}{ Ulam Raja } & SUR.XLD 1 & 99.9\% Citrobacter youngae & 3604112 \\
\hline & & SUR.XLD 3 & 99.8\% Citrobacter youngae & 3604512 \\
\hline & & SUR.XLD 9 & 99.8\% Citrobacter youngae & 3604512 \\
\hline & & SUR.XLD 10 & 99.8\% Citrobacter youngae & 3604512 \\
\hline & \multirow{4}{*}{ Pegaga } & SP.XLD 3 & 99.8\% Citrobacter youngae & 3604512 \\
\hline & & SP.XLD 4 & 99.8\% Citrobacter youngae & 3604512 \\
\hline & & SP.XLD 5 & $99.0 \%$ Citrobacter youngae & 3605512 \\
\hline & & SP.XLD 6 & 99.8\% Citrobacter youngae & 3604512 \\
\hline & \multirow{3}{*}{$\begin{array}{c}\text { Long Bean } / \text { Kacang } \\
\text { Panjang }\end{array}$} & SMKP.XLD 1 & 99.8\% Citrobacter youngae & 3604512 \\
\hline & & SMKP.XLD 3 & $99.0 \%$ Citrobacter youngae & 3605512 \\
\hline & & SMKP.XLD 4 & 99.8\% Salmonella enterica ssp Arizonae & 7704512 \\
\hline & \multirow{4}{*}{ Bean sprout/Tauge } & SMT.XLD 1 & 99.8\% Salmonella enterica ssp Arizonae & 7704572 \\
\hline & & SMT.XLD 2 & 99.8\% Salmonella enterica ssp Arizonae & 7704512 \\
\hline & & SMT.XLD 3 & 99.8\% Salmonella enterica ssp Arizonae & 7704512 \\
\hline & & SMT.XLD.RVS 1 & 99.8\% Salmonella enterica ssp Arizonae & 7704512 \\
\hline & \multirow{4}{*}{ Selom } & SMS.XLD 1 & 99.8\% Citrobacter youngae & 3604512 \\
\hline & & SMS.XLD 2 & 99.8\% Citrobacter youngae & 3604113 \\
\hline & & SMS.XLD 4 & 99.8\% Citrobacter youngae & 3604113 \\
\hline & & SMS.XLD 5 & 99.8\% Citrobacter youngae & 3604113 \\
\hline
\end{tabular}


Table 12. The distribution of 6 Salmonella spp. isolates by type of samples and location

\begin{tabular}{cccc}
\hline Location & Sample & Total number of isolates $(\%)$ & Isolates coding \\
\hline \multirow{2}{*}{ Supermarket } & Tauge & $4(66.6)$ & $\begin{array}{c}\text { SMT.XLD1, SMT.XLD2, } \\
\text { SMT.XLD3.SMT.XLD.RVS1 }\end{array}$ \\
\cline { 2 - 4 } & Kacang panjang & $1(16.7)$ & SMKP.XLD4 \\
\hline Wet Market & Selom & $1(16.7)$ & WMS.HE.TT2 \\
\hline Total & & $6(100)$ & \\
\hline
\end{tabular}

was detected in 600 samples of bean sprout produced in Italy (Lucilla et al., 2017).

\section{Conclusion}

This study provides information on the microbiological quality of ulam sold in supermarkets and wet markets in Kuala Terengganu, Terengganu, Malaysia. The findings showed that all ulam samples were contaminated with bacteria. The microbial load of ulam samples were in the range of 6.36-8.83; 4.14-7.48; 0-8.16; 3.94-6.45 $\log _{10} \mathrm{CFU} / \mathrm{g}$ for aerobic mesophilic bacteria, coliforms, Salmonella spp. and yeast and moulds, respectively. A total of 23 E. coli and 6 Salmonella enterica ser. Arizonae were identified by API20E. All presumptive E. coli and Salmonella isolates were also confirmed as Gram-negative rod-shaped bacteria and oxidase negative. In this study, E. coli was detected in $31.3 \%$ of ulam samples, whereas $9.4 \%$ of samples were found contaminated with Salmonella. The contamination of ulam samples could occur during growth, harvesting, packaging, transportation and distribution. Therefore, good hygiene practices must be implemented by the producers in order to minimise the risk of transmission of foodborne bacteria. Statistically, the total number of coliforms in bean sprout, winged bean, long bean, selom and ulam raja from supermarkets was significantly higher compared to wet market $(\mathrm{p}<0.05)$. Poor handling along the supply chain could have contributed to the high microbial load in the supermarket. Therefore, the employees and customers should always implement a good handling practice to avoid cross-contamination from occurring.

\section{Acknowledgements}

This research was financially supported by University Malaysia Terengganu through TPM Grant Mechanism (Vot No: TPM-68006/2016/84 and Food Safety and Quality Programme (Specific Study on Food Health 2016) by Ministry of Health Malaysia.

\section{References}

Abadias, M., Usall, J., Anguera, M., Solsona, C. and Viñas, I. (2008). Microbiological quality of fresh, minimally-processed fruit and vegetables, and sprouts from retail establishments. International
Journal of Food Microbiology, 123(1-2), 121-129. https://doi.org/10.1016/j.ijfoodmicro.2007.12.013

Abakari, G., Cobbina, S.J. and Yeleliere, E. (2018). Microbial quality of ready-to-eat vegetable salads vended in the central business district of tamale, Ghana. International Journal of Food Contamination, 5(3), 1-9. https://doi.org/10.1186/ s40550-018-0065-2

Acharya, T. (2012). Oxidase test: Principle Procedure and oxidase positive organisms. Retrieved January 19, 2020, from Microbe Online website: https:// microbeonline.com/oxidase-test-principle-procedureand-oxidase-positive-organisms/

Acharya, T. (2013). Triple Sugar Iron Agar (TSI): Principle, Procedure and Interpretation. Retrieved December 27, 2019, from Microbe Online website: https://microbeonline.com/triple-sugar-iron-agar-tsiprinciple-procedure-and interpretation/

Andrews, W.H., Wang, H., Jacobson, A. and Hammack, T. (2011). Bacteriological Analytical Manual (BAM) Chapter 5: Salmonella | FDA. Retrieved November 17, 2019, from FDA Website: https://www.fda.gov/ food/laboratory-methods-food/bacteriologicalanalytical-manual-bam-chapter-5-salmonella

Angelo, K.M., Chu, A., Anand, M., Nguyen, T.A., Bottichio, L., Wise, M., Williams, I., Seelman, S., Bell, R., Fatica, M., Lance, S., Baldwin, D., Shannon, K., Lee, H., Trees, E., Strain, E. and Gieraltowski, L. (2015). Outbreak of Salmonella Newport Infections Linked to Cucumbers-United States, 2014. Morbidity and Mortality Weekly Report, 64, 144-147.

Aycicek, H., Oguz, U. and Karci, K. (2006). Determination of total aerobic and indicator bacteria on some raw eaten vegetables from wholesalers in Ankara, Turkey. International Journal of Hygiene and Environmental Health, 209(2), 197-201. https:// doi.org/10.1016/j.ijheh.2005.07.006

Bachok, M.F., Yusof, B.N.M., Ismail, A. and Hamid, A.A. (2014). Effectiveness of traditional Malaysian vegetables (ulam) in modulating blood glucose levels. Asia Pacific Journal of Clinical Nutrition, 23 (3), 369-376.

Bahri, A.A., Salleh, W., Lani, M.N. and Wan Abdullah, W.Z (2019). Antimicrobial Resistance of Escherichia coli Isolated of Ulam from 
Supermarkets and Wet Markets in Kuala Terengganu, Malaysia. Malaysian Applied Biology Journal, 48(3), 35-42.

Bahri, A.A., Wan Abdullah, W.Z., Lani, M.N., Salleh, W. and Alias, R. (2020). Genotypic and Phenotypic Characteristics Associated with Biofilm Formation in Escherichia coli and Salmonella spp. Isolated from Ulam in Terengganu. Food Research, 4(1), 91 - 101. https://doi.org/10.26656/fr.2017.4(1).240

Bouchrif, B., Paglietti, B., Murgia, M., Piana, A., Cohen, N., Ennaji, M.M., Rubino, S. and Timinouni, M. (2009). Prevalence and antibiotic-resistance of Salmonella isolated from food in Morocco. Journal of Infection in Developing Countries, 3(1), 35-40. https://doi.org/10.3855/jidc.103

Buyukunal, S.K., Issa, G., Aksu, F. and Vural, A. (2015). Microbiological Quality of Fresh Vegetables and Fruits Collected from Supermarkets in Istanbul, Turkey. Journal of Food and Nutrition Sciences, 3 (4), 152-159. https://doi.org/10.11648/ j.jfns. 20150304.13

Cappuccino, J.G. and Sherman, N. (2014). Microbiology: A Laboratory Manual. $10^{\text {th }}$ ed. Rockland, USA: Pearson Education.

CDC (Centers for Disease Control and Prevention). (2019). Reports of Selected E. coli Outbreak Investigations. Retrieved January 28, 2020, from CDC website: https://www.cdc.gov/ecoli/ outbreaks.html

Center for Science in the Public Interest. (2009). The Ten Riskiest Foods Regulated by the FDA. Retrieved from CSPINET website: https:// www.cspinet.org/sites/default/files/attachment/ cspi_top_10_fda.pdf

Chaturvedi, M., Kumar, V., Singh, D. and Kumar, S. (2013). Assessment of microbial load of some common vegetables among two different socioeconomic groups. International Food Research Journal, 20(5), 2927-2931.

Da Silva, S.R.P., Verdin, S.E.F., Pereira, D.C., Schatkoski, A.M., Rott, M.B. and Corção, G. (2007). Microbiological quality of minimally processed vegetables sold in Porto Alegre, Brazil. Brazilian Journal of Microbiology, 38(4), 594-598. https:// doi.org/10.1590/S1517-83822007000400003

FAO/WHO (Food and Agriculture Organization of the United Nations, and World Health Organization). (2008). Microbiological hazards in fresh fruits and vegetables. Microbiological Risk Assessment Series. Rome: FAO/WHO

FDA (Food and Drug Administration). (2016). FDA Investigates Multistate Outbreak of Salmonella
Infections Linked to Alfalfa Sprouts. Retrieved January 29, 2020, from FDA website: https:// www.fda.gov/food/outbreaks-foodborne-illness/fdainvestigates-multistate-outbreak-salmonellainfections-linked-alfalfa-sprouts

Feng, P., Weagant, S.D. and Jinneman, K. (2011). BAM: Diarrheagenic Escherichia coli. Retrieved November 17, 2019, from FDA website: https://www.fda.gov/ food/laboratory-methods-food/bam-diarrheagenicescherichia-coli

Food Standards Australia New Zealand. (2016). Compendium of Microbiological Criteria for Food. Retrieved from Food Standards Australia New Zealand Website: https://www.foodstandards.gov.au/ publications/Documents/Compedium\%20of\% 20Microbiological\%20Criteria/ Compendium_revised-Sep\%202018.pdf

Gruda, N. (2005). Impact of Environmental Factors on Product Quality of Greenhouse Vegetables for Fresh Consumption. Critical Reviews in Plant Sciences, 24 (3) 227-247. https:// doi.org/10.1080/07352680591008628

Hassan, Z.H. and Purwani, E.Y. (2016). Microbiological aspect of fresh produces as retailed and consumed in West Java, Indonesia. International Food Research Journal, 23(1), 350-359.

Herman, K.M., Hall, A.J. and Gould, L.H. (2015). Outbreaks attributed to fresh leafy vegetables, United States, 1973-2012. Epidemiology and Infection, 143(14), 3011-3021. https:// doi.org/10.1017/S0950268815000047

Holmes, B., Willcox, W.R. and Lapage, S.P. (1978). Identification of Enterobacteriaceae by the API $20 \mathrm{E}$ system. Journal of Clinical Pathology, 31(1), 22-30. https://doi.org/10.1136/jcp.31.1.22

James, Y., Gambo, J.B. and Aliyu, A.M. (2019). Microbiological Assessment of Some Vegetables Obtained from Irrigated farms within Kaduna Metropolis. Journal of Pharmacy and Biological Sciences, 14(3), 26-30.

Jeddi, M.Z., Yunesian, M., Gorji, M.E., Noori, N., Pourmand, M.R. and Khaniki, G.R.J. (2014). Microbial Evaluation of Fresh, Minimally-processed Vegetables and Bagged Sprouts from Chain Supermarkets. Journal of Health, Population and Nutrition, 32(3), 391-399.

Kim, Y.J., Kim, H.S., Kim, K.Y., Chon, J.W., Kim, D.H. and Seo, K.H. (2016). High Occurrence Rate and Contamination Level of Bacillus cereus in Organic Vegetables on Sale in Retail Markets. Foodborne Pathogens and Disease, 13(12), 656-660. https:// doi.org/10.1089/fpd.2016.2163 
Kuan, C.H., Rukayadi, Y., Ahmad, S.H., Wan Mohamed Radzi, C.W.J., Thung, T.Y., Premarathne, J.M.K.J.K., Chang, W.S., Loo, Y.Y., Tan, C.W., Ramzi, O.B., Mohd Fadzil, S.N., Kuan, C.S., Yeo, S.K., Nishibuchi, M. and Radu, S. (2017). Comparison of the Microbiological Quality and Safety between Conventional and Organic Vegetables Sold in Malaysia. Frontiers in Microbiology, 8, 1433. https://doi.org/10.3389/ fmicb.2017.01433

Lucilla, I., Federica, G., Debbie, A. and Comi, G. (2017). Microbial Quality of Raw and Ready-To-Eat Mung Bean Sprouts Produced in Italy. Nutritional and Food Science International Journal, 3(1), 555601. https://doi.org/10.19080/NFSIJ.2017.03.555601

Mritunjay, S.K. and Kumar, V. (2015). Fresh farm produce as a source of pathogens: A review. Research Journal of Environmental Toxicology, 9 (2), 59-70. https://doi.org/10.3923/rjet.2015.59.70

Mritunjay, S.K. and Kumar, V. (2017). A study on prevalence of microbial contamination on the surface of raw salad vegetables. 3 Biotech, 7, 13. https:// doi.org/10.1007/s13205-016-0585-5

Najafi, M.B.H. and Bahreini, M. (2012). Microbiological Quality of Mixed Fresh-Cut Vegetable Salads and Mixed Ready- to-Eat Fresh Herbs in Mashhad, Iran. International Conference on Nutrition and Food Sciences IPCBEE, 39, 62-66.

Neogen Coorporation. (2017). Lysine Iron Agar (7211). Retrieved November 17, 2019, from Neogen website: https://foodsafety.neogen.com/pdf/ acumedia_pi/7211_pi.pdf

New, C.Y., Ubong, A., Premarathne, J.M.K.J.K., Thung, T.Y., Lee, E., Chang, W.S., Loo, Y.Y., Kwan, S.Y., Tan, C.W., Kuan, C.H., and Son, R. (2017). Microbiological food safety in Malaysia from the academician's perspective. Food Research, 1(6), 183 -202. https://doi.org/10.26656/fr.2017.6.013

Nguz, K., Shindano, J., Samapundo, S. and Huyghebaert, A. (2005). Microbiological evaluation of fresh-cut organic vegetables produced in Zambia. Food Control, 16(7), 623-628. https://doi.org/10.1016/ j.foodcont.2004.07.001

NSW Food Authority. (2009). Microbiological quality guide for ready to-eat foods. A guide to interpreting microbiological results. Retrieved from website: https://www.foodauthority.nsw.gov.au/sites/default/ files/_Documents/scienceandtechnical/ microbiological_quality_guide_for_RTE_food.pdf

Nyenje, M.E., Odjadjare, C.E., Tanih, N.F., Green, E., and Ndip, R.N. (2012). Foodborne Pathogens Recovered from Ready-to-Eat Foods from Roadside
Cafeterias and Retail Outlets in Alice, Eastern Cape Province, South Africa: Public Health Implications. International Journal of Environmental Research and Public Health, 9(8), 2608-2619. https:// doi.org/10.3390/ijerph9082608

PHE (Public Health England). (2019). UK Standards for Microbiology Investigations: Oxidase test. Issue 4, p. 1-15. Retrieved from PHE website: https:// assets.publishing.service.gov.uk/government/ uploads/system/uploads/attachment_data/ file/771781/TP_26i4.pdf

Ponniah, J., Robin, T., Paie, M.S., Radu, S., Ghazali, F.M., Kqueen, C.Y., Nishibuchi, M. and Malakar, P.K. (2010). Listeria monocytogenes in raw salad vegetables sold at retail level in Malaysia. Food Control, 21(5), 774-778. https://doi.org/10.1016/ j.foodcont.2009.09.008

Pui, C.F., Wong, W.C., Chai, L.C., Tunung, R., Jeyaletchumi, P., Noor Hidayah, M.N., Ubong, A., Farinazleen, M.G., Cheah, Y.K. and Son, R. (2011). Salmonella: A foodborne pathogen. International Food Research Journal, 18(2), 465-473.

Sagoo, S.K., Little, C.L., Ward, L., Gillespie, I.A. and Mitchell, R.T. (2003). Microbiological Study of Ready-to-Eat Salad Vegetables from Retail Establishments Uncovers a National Outbreak of Salmonellosis. Journal of Food Protection, 66(3), 403-409. https://doi.org/10.4315/0362-028X66.3.403

Sair, A.T., Masud, T., Sohail, A. and Rafique, A. (2017). Microbiological variation amongst fresh and minimally processed vegetables from retail establishers-A public health study in Pakistan. Food Research, 1(6), 249-255. https://doi.org/10.26656/ fr.2017.6.060

Salleh, W., Lani, M.N., Abdullah, W.Z.W., Chilek, T.Z.T. and Hassan, Z. (2017). A review on incidences of foodborne diseases and interventions for a better national food safety system in Malaysia. Malaysian Applied Biology, 46(3), 1-7.

Sant'Ana, A.S., Igarashi, M.C., Landgraf, M., Destro, M.T. and Franco, B.D.G.M. (2012). Prevalence, populations and pheno- and genotypic characteristics of Listeria monocytogenes isolated from ready-to-eat vegetables marketed in Sao Paulo, Brazil. International Journal of Food Microbiology, 155, 19. https://doi.org/10.1016/j.ijfoodmicro.2011.12.036

Seltzer, J.M., Rush, J. and Kinsey, J. (2009). Natural Selection: 2006 E. coli Recall of Fresh Spinach: USA: The Food Industry Center, University of Minnesota. 
Seow, J., Agoston, R., Phua, L. and Yuk, H.G. (2012). Microbiological quality of fresh vegetables and fruits sold in Singapore. Food Control, 25(1), 39-44. https://doi.org/10.1016/j.foodcont.2011.10.017

Tallent, S.M., Knolhoff, A., Rhodehamel, E.J., Harmon, S.M. and Bennett, R.W. (2019). Bacteriological Analytical Manual Chapter 14 Bacillus cereus. Retrieved November 17, 2019, FDA Website: from https://www.fda.gov/food/laboratory-methods-food/ bam-bacillus-cereus

Thunberg, R.L., Tran, T.T., Bennett, R.W., Matthews, R.N. and Belay, N. (2002). Microbial Evaluation of Selected Fresh Produce Obtained at Retail Markets. Journal of Food Protection, 65(4), 677-682. https:// doi.org/10.4315/0362-028X-65.4.677

United States Department of Agriculture-Food Safety and Inspection Service (USDA-FSIS). (2013). Isolation and Identification of Listeria monocytogenes from Red Meat, Poultry and Egg Products, and Environmental Samples. Laboratory Quality Assurance Division (LQAD). USA: USDA.

Wardani, T.S. (2019). Analysis of Bacteria Content Escherichia coli on Ice Cube for Sale in the Sondakan Area of Surakarta, presented at the International Conference of Health, Science and Technology (ICOHETECH), p. 145-148. Solo, Indonesia: Universitas Duta Bangsa Surakarta 